\title{
Cervical Cancer Screening Uptake and Determinant Factors Among Women in Ambo Town, Western Oromia, Ethiopia: Community based Cross Sectional Study
}

Shewaye Fituma Natae ( $\nabla$ nataeshewaye@gmail.com )

Ambo University

Digafe Tsegaye Nigatu

Ambo University

Mulu Kitaba Negawo

Ambo University

Wakeshe Willi Mengesha

Ambo University

\section{Research Article}

Keywords: Cervical cancer screening uptake, determinant factors, Ethiopia

Posted Date: March 3rd, 2021

DOI: https://doi.org/10.21203/rs.3.rs-257946/v1

License: (c) (i) This work is licensed under a Creative Commons Attribution 4.0 International License. Read Full License

Version of Record: A version of this preprint was published at Cancer Medicine on October 27th, 2021. See the published version at https://doi.org/10.1002/cam4.4369. 


\section{Abstract}

Background: Cervical cancer is one of the principal causes of cancer death among women worldwide. It is the second most common cancer and the leading cause of cancer-related death in Ethiopian women; about 77.6\% of women died of 6,294 new cases reported in 2019. Early screening for cervical cancer has substantial advantage to reduce the incidence, morbidity, and mortality attributed to cervical cancer. So far, there are limited evidence on the level of cervical cancer screening uptake and its determinant in low- and middle-income countries including Ethiopia. Consequently, the current study aimed to assess the level of cervical cancer screening uptake and its determinant among women of Ambo town, western Oromia, Ethiopia.

Methods: A community-based cross-sectional study was conducted among 422 women aged 20-65years. Systematic random sampling was employed to recruit the eligible women from randomly selected sub-districts found in Ambo town. Interviewer-administered questionnaire was used to collect the data. Epi info was used for data entry and management from which it was exported to SPSS version 25 for detailed analysis. Variables in binary logistic regression with a $p$-value $<0.25$ were candidate for multivariable logistic regression. Estimates were presented using odds ratios (ORs) with $95 \% \mathrm{Cl}$. Statistical Significance was declared at $p$ value $<0.05$.

Results: In the present study 392 women were participated giving a response rate of $93 \%$. Overall, $63 \%$ of the respondents were known the availability of cervical cancer screening service. Only $8.7 \%$ (34) of the study participants were received cervical cancer screening in their lifetime. Being in the age group of 30-39 years $(A O R=3.2 ; 95 \% \mathrm{Cl}[1.22,8.36])$ and 40-49years (AOR=4.8; 95\% Cl $[1.42,16.41])$, having cervical cancer related discussion with health care provider (AOR=3.5; $95 \% \mathrm{Cl}[1.17,10.7])$, and knowing availability cervical cancer screening service (AOR=2.8; 95\% Cl [1.03, 7.87]) were significantly associated with uptake of cervical cancer screening.

Conclusion: In this study, cervical cancer screening uptake is very low. The study also highlighted important factors that affect uptake of cervical cancer screening service. Therefore, this study result call urgent interventions by all stockholders to increase cervical cancer service uptake through continues promotions and by securing its availability and accessibility for all eligible women at all levels.

\section{Introduction}

Cervical cancer (CC) is the fourth most prevalent leading cause of cancer deaths among women worldwide; accounting for 311,000 women's deaths annually $(1,2)$. More than $99 \%$ of the cervical cancer cases result due to infection with high-risk human papillomaviruses (HPV) (HPV subtypes 16 and 18), which is transmitted through sexual contact $(3,4)$. Cervical cancer-related mortality is reducing in affluent countries since the launch of the formal screening program (5). In contrast, the burden and mortality as a result of $\mathrm{CC}$ are increasing in low and middle-income countries (LMICs) due to the absence of well-organized screening and HPV vaccination services $(4,6,7)$. According to 2015 report, of 270,000 cervical cancer deaths, 243,000 was occurred in LMICs (4).

In Africa, cervical cancer is the leading cause of cancer-specific mortality in women. The incidence of cervical cancer is high in Sub-Saharan African (SSA) countries; it was $24 \%$ in the 2013 report (8). The disease is steadily increasing and result in more than 75,000 new cases and 50,000 deaths per year in SSA $(9,10)$. Of the African 
countries, the burden of cervical cancer is higher in southern Africa. In 2018 the incidence of CC was $43.1 \%$ with a $20 \%$ mortality rate (11). Scientists predicted that by the year 2030 , more than 443,000 women die of CC; and the majority $(398,700)$ of the deaths will occur in $\operatorname{SSA}(1,12)$. Ethiopia also shares a high incidence of cervical cancer. About 4,884 Ethiopian women died of 6,294 new cases reported in 2019 by the HPV information center of the country (13). Cervical cancer is the second most common cancer and the principal cause of cancer related death among Ethiopian women (14).

There are strategies launched by the World Health Organization (WHO) for controlling and prevention CC and its consequences. Vaccination for HPV and screening for eligible women are some of the proposed strategies (15, 16). Vaccination for the high-risk subtypes of HPV (5) is the primary preventive mechanism of CC (16). Infection by high-risk human papillomaviruses (HPV 16 and 18) reduced by $70 \%$ in countries where at least $50 \%$ of eligible females were vaccinated (17). Moreover, screening for the HPV at the early stage of the disease was more efficient for detecting cervical pre-cancers and provided high protection against cervical cancer $(5,18,19)$.

In high-income countries, the screening methods shifts from cytology-based to molecular screening, and cotesting to achieve the anticipated goals (6). On the other hand, visual inspection with acetic acid (VIA), HPV testing-based screening, and a "single-visit screen and treat"(20) are the alternative screening methods in LMICs $(6,21)$. Cervical cancer incidence $(25 \%)$ and mortality $(35 \%)$ was reduced as a result of a single round screening with VIA (22). Moreover, a randomized control trial (RCT) in rural India revealed a significant reduction of advanced cervical cancer (53\%) and deaths (48\%) with a single round screening with high risk- HPV testing compared with the existing standard of care only for opportunistic screening (23).

Though, WHO recommended screening of women aged 30-49years (24) and screening for cervical cancer between age 21 to 65years substantially reduces cervical cancer incidence (25), advanced stage of the disease (23), and mortality $(22,23,25,26)$; still, there are different barriers that hinder the utilization of the screening services. Absence of linkage of diagnosis and treatment (6), traditional practices and beliefs $(27,28)$, socioeconomic status (29-31), public awareness (31, 32), fear of cancer and out-comes of screening (31-33), and health care access $(30,31,33)$ are barriers of cervical cancer screening uptake mainly in LMICs. A few qualitative studies identified the lack of understanding of the benefits of the screening as barriers to CC screening in LMICs $(28,31)$. A systematic literature review indicated that lack of partner support, social stigmatization, cost of the services, and health care providers' attitudes were barriers to cervical cancer screening service utilization in SSA (33).

Studies have shown that education intervention and self-sampling for HPV testing increased cervical cancer screening rates by fold $(34,35)$. Likewise, awareness of cervical cancer, family history of the disease, and experiencing the signs and symptoms of the disease were facilitators for the utilization of screening services by the women (31). In the study area, data related to the level of CC screening uptake and determinant factors is lacking: thus, the present study aimed to assess the level of cervical cancer screening uptake and determinant factors among women of Ambo town, western Oromia, Ethiopia.

\section{Methods}

\section{Study area, period, and participants}


A community-based cross-sectional study was conducted from December 01, 2017 to January 30, 2017, in Ambo town capital of west Shewa zone, western Ethiopia. The town is located 114 kilometres to the west of Addis Ababa.

According to the health planning, monitoring, and evaluation department report, the town has a total of 97,317 population, of which $18.6 \%$ of them were women of reproductive age group.

In Ambo town there are six sub-districts, one general, one referral and teaching hospital, two health centers, one Maternal and child health $(\mathrm{MCH})$ clinic, and twenty private clinics that were providing different reproductive health services in the town. Currently, it is only the government hospitals that providing cervical cancer screening services. All women aged between 20 and 65 years who are residing in Ambo town were the source population. Consequently, randomly selected women aged 20-65years (25) and who reside in the town during the data collection period were the sample population.

\section{Sample size and sampling procedure}

The sample size was calculated by using the single population proportion formula with the assumption of $95 \%$ $\mathrm{Cl}, 50 \%$ proportion of women who uptake cervical cancer screening services, and $5 \%$ margin of error was used to obtain a sample size of 384, with adjustment of 10\% non-response, the final sample size was 422 .

$$
n=\frac{1.96^{2} * 0.5(1-0.5)}{0.05^{2}}=384
$$

From six sub-districts of Ambo town, three sub-districts; namely sub-districts 01,02 , and 06 were selected by a simple random sampling technique. A total of 6705,3513 , and 3306 eligible women were found in sub-districts 01, 02 and 06, respectively. From those respective sub-districts the sample size for this study was proportionally allocated; accordingly, 209,109, and 103 women were selected from sub-districts 01, 02, and 06, respectively. Study participants were selected by systematic random sampling technique. The first household with eligible subject was selected by the lottery method and then every 36th household with eligible subject were included in the study. Women aged 20-65years were interviewed from the selected households and if there were more than one woman in the household, the lottery method was used to select one.

\section{Data collection tools and data collectors}

The questionnaire was adapted from similar studies conducted in Gonder town (36), Jimma (37), and India (38). It was first prepared in English and then translated to local language (Afan Oromo) and back-translated into English by language experts to ensure its consistency. An interviewer-administered pre-tested questionnaire was used for data collection. A pre-test was done on $5 \%$ women live in different sub-districts to avoid contamination of information. The data were collected by six BSc Nurses and supervised by two MSc Nurses. Data collectors and supervisors were trained for two days before data collection. Personal identifiers were not included in the questionnaires to ensure the participants' confidentiality. Supervisors and principal investigator checked the completeness of the questionnaires daily.

The tool covers variables like: socio-demographic characteristics, reproductive and sexual history, cervical cancer and screening knowledge, and cervical cancer screening uptake. 


\section{Operational definitions}

\section{Cervical cancer screening uptake}

The proportion of women who have ever been screened for cervical cancer at least once in their life time (39).

\section{Data processing and analysis}

Data were coded, entered, and cleaned using Epi info version 3.5.1 and exported to SPSS version 25 statistical package for analyses. Descriptive statistics were computed and presented using tables and figures. The outcome variable is dichotomous coded as " 1 " when the respondents were screened for CC, otherwise " 0 ". Frequencies and proportions were calculated for a description related to socio-demographic and other variables. Relationships between dependent and independent variables investigated using the Binary logistic regression model. Those variables with p-value below 0.25 in bivariate logistic regression were included in a multivariate logistic regression model for controlling potential confounding effects. The independent predictors for cervical cancer screening uptake are presented using adjusted odds ratio (AOR) with its $95 \% \mathrm{Cl}$. A statistical significance was established as $p<0.05$.

\section{Results}

\section{Socio-demographic characteristics}

A total of 392 women aged $20-65 y e a r s$ old interviewed making a $92.9 \%$ response rate. The mean age of the study participants was 30.1 years $( \pm 9.1 \mathrm{SD})$. The majority $(96.4 \%)$ of the respondents were from the Oromo ethnic group. About two-third of the women were married, and $117(29.8 \%)$ of them completed college and above. Nearly half (48\%) of the women were housewives in their occupation (Table 1). 
Table 1

Socio-demographic characteristics of study participants in Ambo town western Oromia, Ethiopia, December-January 2017

\begin{tabular}{|c|c|c|c|}
\hline Variable $(n=392)$ & Category & Frequency & Percentage \\
\hline \multirow[t]{4}{*}{ Age(yrs) } & $20-29$ & 228 & 58.2 \\
\hline & $30-39$ & 109 & 27.8 \\
\hline & $40-49$ & 34 & 8.7 \\
\hline & $>49$ & 21 & 5.4 \\
\hline \multirow[t]{2}{*}{ Ethnicity } & Oromo & 378 & 96.4 \\
\hline & Others* & 14 & 3.6 \\
\hline \multirow[t]{3}{*}{ Religion } & Orthodox & 151 & 38.5 \\
\hline & Protestant & 228 & 58.2 \\
\hline & Others** & 13 & 3.3 \\
\hline \multirow[t]{4}{*}{ Marital status } & Single & 97 & 24.7 \\
\hline & Married & 254 & 64.8 \\
\hline & Divorced & 17 & 4.3 \\
\hline & Widowed & 24 & 6.2 \\
\hline \multirow[t]{4}{*}{ Educational status } & Illiterate & 67 & 17.1 \\
\hline & Attend primary & 103 & 26.3 \\
\hline & Attend secondary & 105 & 26.8 \\
\hline & College and above & 117 & 29.8 \\
\hline \multirow[t]{5}{*}{ Occupation } & House wife & 88 & 48 \\
\hline & Private employee & 42 & 10.7 \\
\hline & Governmental employee & 80 & 20.4 \\
\hline & Daily laborer & 38 & 9.7 \\
\hline & Student & 44 & 11.2 \\
\hline \multirow[t]{3}{*}{ Income } & No income & 37 & 9.4 \\
\hline & 100-1000 ET birr & 157 & 40.1 \\
\hline & >1000 ET birr & 198 & 50.5 \\
\hline
\end{tabular}

Reproductive characteristics of the respondents 
About 256 (65.3\%) of the participants had a single sexual partner, while the rest (34.7\%) had multiple sexual partners in their lifetime.

Two hundred and forty-three (62.0\%) of the participants had two and above pregnancies (Table 2).

Table 2

Reproductive characteristics of the study participants in Ambo town, western Oromia, Ethiopia, December-January 2017

\begin{tabular}{|c|c|c|c|}
\hline \\
\hline Variable $(n=392)$ & Category & Frequency & Percent \\
\hline \multirow[t]{2}{*}{ Age at first intercourse } & $<18$ years & 159 & 40.6 \\
\hline & $\geq 18$ years & 233 & 59.4 \\
\hline \multirow[t]{2}{*}{ Have you been pregnant } & Yes & 324 & 82.7 \\
\hline & No & 68 & 17.3 \\
\hline \multirow[t]{2}{*}{ Number of pregnancy } & $<2$ & 149 & 38.0 \\
\hline & $\geq 2$ & 243 & 62.0 \\
\hline \multirow[t]{2}{*}{ Have you give birth } & Yes & 300 & 76.5 \\
\hline & No & 92 & 23.5 \\
\hline \multirow[t]{2}{*}{ Number of children } & $<2$ & 156 & 39.8 \\
\hline & $\geq 2$ & 236 & 60.2 \\
\hline \multirow[t]{2}{*}{ Lifetime number of sexual partner } & Single partner & 256 & 65.3 \\
\hline & Multiple partner & 136 & 34.7 \\
\hline \multirow[t]{2}{*}{ History of abortion } & Yes & 47 & 12.0 \\
\hline & No & 345 & 88.0 \\
\hline \multirow[t]{2}{*}{ History of contraceptive use } & Yes & 208 & 53.1 \\
\hline & No & 184 & 46.9 \\
\hline
\end{tabular}

\section{Knowledge of cervical cancer}

Three hundred and eight (78.6\%) subjects have ever heard of cervical cancer; mass media was the most sources of information reported by study subjects (Fig. 1).

Of the study participants, only $180(45.9 \%)$ of them know of cervical cancer, while more than half (54.1\%) of the women did not know cancer of the cervix.

Most (68.3\%) of the women reported unusual vaginal bleeding as the symptom of CC, while the rest reported vaginal discharge mixed with blood (42.2\%), dyspareunia (32.2\%), pelvic pain (12.8\%), and the least reported back pain $(2.2 \%)$ as the symptom of CC. Regarding the preventive mechanisms of cervical cancer, only $45(11.5 \%)$ and $15(3.8 \%)$ of the women knew HPV vaccination and screening for cervical cancer prevent CC, respectively. 


\section{Cervical cancer screening uptake and reason for not getting screened}

Only 34 (8.7\%) of the women had ever screened for cervical cancer in their lifetime. However, $247(63.0 \%)$ of the women had knowledge about cervical cancer screening.

Papanicolaou (Pap) test (44.1\%) was the most screening type reported by respondents who had ever screened for cervical cancer, followed by a blood test (35.3\%), and visual inspection with acetic acid (VIA) (20.6\%). Not getting sick of CC is the main reason for non-utilization of CC screening services (Fig. 2).

\section{Factors associated with uptake of cervical cancer screening}

In bivariate logistic regression analysis: age, knowing the availability of the screening service in the public hospital, history of early sexual initiation, know the consequence of advanced cervical cancer (metastasis and bleeding), knowledge of CC screening, and discussion on cervical cancer with health care providers were statistically significant with the uptake of cervical cancer screening.

However, in multivariable logistic regression analysis; age, knowledge on the consequence of advanced cervical cancer (metastasis and bleeding), knowledge of CC screening, and discussion with health care provider on CC screening were remained significantly associated with cervical cancer screening uptake (Table 3).

This study indicated that those women who were in the age group of 30-39 years and 40-49 years were 3.2 times $(A O R=3.2 ; 95 \% \mathrm{Cl}[1.22,8.36])$ and 4.8 times $(\mathrm{AOR}=4.8 ; 95 \% \mathrm{Cl}[1.42,16.41])$ more likely to uptake cervical cancer screening compared to those women whose ages between 20-29years, respectively. Those women who knew giving birth to many children as risk factor for cervical cancer were 2.7 times $(\mathrm{AOR}=2.7 ; 95 \% \mathrm{Cl}[1.26$, 5.98]) more likely to utilize cervical cancer screening compared to their counterparts. Women who had knowledge about cervical cancer screening were 2.8 times ( $\mathrm{AOR}=2.8 ; 95 \% \mathrm{Cl}[1.03,7.87])$ more likely to uptake cervical cancer screening than their counterparts. Furthermore, the present study found that knowledge on the consequences of advanced cervical cancer increases the uptake of cervical cancer screening by the study subjects. Those women who knew metastasis and bleeding were the consequence of advanced cervical cancer were 2.9 times $(\mathrm{AOR}=2.9 ; 95 \% \mathrm{Cl}[1.20,6.95])$ and 3.1 times $(\mathrm{AOR}=3.1 ; 95 \% \mathrm{Cl}[1.16,8.29])$ more likely to utilize the CC screening service than their counterparts, respectively. 
Table 3

Determinants of cervical cancer screening uptake among women of Ambo town, western Oromia, Ethiopia, December-January 2017

\begin{tabular}{|c|c|c|c|c|c|}
\hline \multirow[t]{3}{*}{ Variables } & \multirow[t]{3}{*}{ Total } & \multicolumn{2}{|c|}{$\begin{array}{l}\text { Cervical cancer screening } \\
\text { uptake }\end{array}$} & \multirow[t]{3}{*}{$\mathrm{COR}, 95 \% \mathrm{Cl}$} & \multirow[t]{3}{*}{$\mathrm{AOR}, 95 \% \mathrm{Cl}$} \\
\hline & & Yes & No & & \\
\hline & & No(\%) & $\mathrm{No}(\%)$ & & \\
\hline \multicolumn{6}{|l|}{ Age(yrs) } \\
\hline $20-29$ & 228 & $10(4.4)$ & 218(95.6) & 1.00 & 1.00 \\
\hline $30-39$ & 109 & $14(12.8)$ & $95(87.2)$ & $3.2(1.38,7.5)^{\star}$ & $3.2(1.22,8 \cdot 36)^{\star}$ \\
\hline $40-49$ & 34 & $6(17.6)$ & $28(82.4)$ & $4.7(1.57,13.84)^{\star}$ & $4.8(1.42,16.41)^{\star}$ \\
\hline$>49$ & 21 & $4(19.0)$ & 17(81.0) & $5.1(1.46,18.09)^{\star}$ & $4.3(0.94,19.58)$ \\
\hline \multicolumn{6}{|l|}{ Education status } \\
\hline Illiterate & 67 & $8(11.9)$ & $59(88.1)$ & 1.00 & 1.00 \\
\hline Attend primary education & 103 & 12(11.7) & $91(88.3)$ & $1.0(0.38,2.52)$ & $1.1(0.42,3.09)$ \\
\hline $\begin{array}{l}\text { Attend secondary } \\
\text { education }\end{array}$ & 105 & $7(6.7)$ & 98(93.3) & $0.5(0.18,1.53)$ & $0.8(0.26,2.43)$ \\
\hline College and above & 117 & $7(6.0)$ & $110(94.0)$ & $0.5(0.16,1.36)$ & $0.9(0.26,2.89)$ \\
\hline \multicolumn{6}{|l|}{ Marital status } \\
\hline Single & 97 & $5(5.2)$ & $92(94.8)$ & 1.00 & 1.00 \\
\hline Married & 254 & $24(9.4)$ & 230(90.6) & $1.9(0.71,5.2)$ & $1.0(0.29,3.10)$ \\
\hline Divorced & 27 & $2(7.4)$ & $25(92.6)$ & $1.5(0.27,8.04)$ & $0.5(0.07,3.06)$ \\
\hline Widowed & 14 & $3(21.4)$ & 11(78.6) & $5(1.1,23.93)^{\star}$ & $1.7(0.26,11.48)$ \\
\hline \multicolumn{6}{|l|}{ Income } \\
\hline$<100$ ETH birr & 37 & $1(2.7)$ & $36(97.3)$ & 1.00 & 1.00 \\
\hline 100-1000 ETH birr & 157 & $17(10.8)$ & $140(89.2)$ & $4.4(0.56,33.95)$ & $4.5(0.52,39.22)$ \\
\hline > 1000 ETH birr & 198 & $16(8.1)$ & 182(91.9) & $3.2(0.41,24.63)$ & $2.9(0.32,26.80)$ \\
\hline \multicolumn{6}{|l|}{ Give birth to many children } \\
\hline Yes & 80 & 15(18.8) & $65(81.3)$ & $3.6(1.72,7.37)^{\star}$ & $2.7(1.26,5.98)^{*}$ \\
\hline No & 312 & $19(6.1)$ & 293(93.9) & 1.00 & 1.00 \\
\hline \multicolumn{6}{|l|}{$\begin{array}{l}\text { Screening service } \\
\text { availability }\end{array}$} \\
\hline Yes & 48 & $8(16.7)$ & $40(83.3)$ & $2.5(1.04,5.77)^{\star}$ & $1.9(0.75,4.81)$ \\
\hline No & 344 & $26(7.6)$ & $318(92.4)$ & 1.00 & 1.00 \\
\hline
\end{tabular}




\begin{tabular}{|c|c|c|c|c|c|}
\hline \multirow[t]{3}{*}{ Variables } & \multirow[t]{3}{*}{ Total } & \multicolumn{2}{|c|}{$\begin{array}{l}\text { Cervical cancer screening } \\
\text { uptake }\end{array}$} & \multirow[t]{3}{*}{$\mathrm{COR}, 95 \% \mathrm{Cl}$} & \multirow[t]{3}{*}{ AOR,95\% Cl } \\
\hline & & Yes & No & & \\
\hline & & $\mathrm{No}(\%)$ & No(\%) & & \\
\hline \multicolumn{6}{|c|}{$\begin{array}{l}\text { Early sexual initiation risk } \\
\text { for CC }\end{array}$} \\
\hline Yes & 38 & $9(23.7)$ & $29(76.3)$ & $4.1(1.74,9.57)^{\star}$ & $2.2(0.86,5.70)$ \\
\hline No & 354 & $25(7.1)$ & $329(92.9)$ & 1.00 & 1.00 \\
\hline \multicolumn{6}{|c|}{ Knew metastasis } \\
\hline Yes & 53 & $11(20.8)$ & $42(79.2)$ & $3.6(1.64,7.91)^{\star}$ & $2.9(1.20,6.95)^{\star}$ \\
\hline No & 339 & $23(6.8)$ & $316(93.2)$ & 1.00 & 1.00 \\
\hline \multicolumn{6}{|c|}{ Knew bleeding } \\
\hline Yes & 30 & $9(30.0)$ & $21(70.0)$ & $5.8(2.39,13.93)^{\star}$ & $3.1(1.16,8.29)^{\star}$ \\
\hline No & 362 & $25(6.9)$ & $337(93.1)$ & 1.00 & 1.00 \\
\hline \multicolumn{6}{|c|}{ Knowledge on CC screening } \\
\hline Yes & 247 & $29(11.7)$ & 218(88.3) & $3.7(1.41,9.85)^{\star}$ & $2.8(1.03,7.87)^{\star}$ \\
\hline No & 145 & $5(3.4)$ & $140(96.6)$ & 1.00 & 1.00 \\
\hline \multicolumn{6}{|c|}{$\begin{array}{l}\text { Knowledge on cervical } \\
\text { cancer }\end{array}$} \\
\hline Yes & 180 & 19(10.6) & $161(89.4)$ & $1.6(0.76,3.15)$ & $1.0(0.44,2.16)$ \\
\hline No & 212 & $15(7.1)$ & 197(92.9) & 1.00 & 1.00 \\
\hline \multicolumn{6}{|c|}{ Discussed CC with HCP } \\
\hline Yes & 31 & $6(19.4)$ & $25(80.6)$ & $2.9(1.08,7.54)^{\star}$ & $3.5(1.17,10.7) *$ \\
\hline No & 361 & $28(7.8)$ & $333(92.2)$ & 1.00 & 1.00 \\
\hline \multicolumn{6}{|c|}{ Heard cervical cancer } \\
\hline Yes & 308 & $31(10.1)$ & 277(89.9) & $3.0(0.9,10.14)$ & $2.7(0.73,9.69)$ \\
\hline No & 84 & $3(3.6)$ & $81(96.4)$ & 1.00 & 1.00 \\
\hline
\end{tabular}

\section{Discussion}

A total of 392 women participated in the study gives a response rate of $92.9 \%$. In this study, only $8.7 \%$ of women reported that they ever had a screening for cervical cancer. The finding was similar to a study conducted in llorin, 
North Central Nigeria (8\%) (40) and in Hosanna town (10\%) of Ethiopia (41) .

However, the level of cervical cancer screening uptake of the present study was lower than former studies conducted in Dessie town (11\%) (42), Mekele town (20\%) (43), and Debremarkos town (21\%) of Ethiopia (44). These discrepancies may be due to the difference in service availability in the study area and design, study participants awareness towards CC, and the age of the women included in the studies. In the Bante et al study (44) all the reproductive age group of women were included, whereas the present study included only women in the age group of 20-65years which is eligible for the cervical cancer screening (25). Another study (45), also indicated that $17 \%$ of undergraduate female University students were underwent cervical cancer screening in their life time. The level of screening from this study also higher than that of the present study; the reason might be due to the variation of awareness level among the university students and women in the general community. Studies showed that women who had higher level of education (46-48) and knowledge on cervical cancer (41$43)$, and its screening $(43,47)$ were more utilized the screening services than their counterparts.

Conversely, the cervical cancer screening level of the present study was higher than the community based studies conducted among women in Finote-Selam city (7.3\%), north west Ethiopia (49), in Butajira district, (2.3\%), southern Ethiopia (48), and in Debre Markos town (5.4\%), northwest Ethiopia (47).The inconsistencies might be due to the difference in study setting and age groups included in the studies.

The current study revealed that: age (being within the age group of 30-39yrs and 40-49yrs), knew metastasis and bleeding are the consequences of advanced CC, and Knowledge on CC screening, discussion with health care provider on CC screening, and give birth to many children were predictors of cervical cancer screening uptake. Women in the age group of 30-39years (3.2 times) and 40-49years (4.8 times) more likely to be screened for cervical cancer compared to the reference group (those aged between 20-29years). The finding was in line with studies conducted in public hospitals found in the Tigray region (50) and Mekele town (43) that reported being aged between 30-39years were 2 times more likely to utilize screening services than those who were 2129years old. Moreover, the likely hood of cervical cancer screening uptake is increasing as age increased. Those women whose age ranges 40-49years were 4 times (50), 3.1times (47) and 2.4 times (51) more likely to utilize the screening services compared to 21-29 years old. Also studies conducted in Dessie town (42), Debre Markos town (44), and Finote Selam city (49) revealed that women aged between 34-49 years were, 6.0 times, 3.2 times, and 2.8 times more likely to be screened for CC than the younger age group, respectively.

Had a discussion with health care providers about cervical cancer screening was also increasing its utilization; those women who had ever discussed with the health care providers about CC screening were 3.5times more likely to be screened than their counterparts.

This finding also supported by studies conducted in Debre-Markos town and Bahir-Dar city (44, 52), which revealed that being informed about CC screening by health professionals increases its utilization by 6.8 folds. Former studies also indicated that knowledge on cervical cancer screening was increased CC screening uptake by 2.36 fold (43) and by 4.02 fold (47). The present study also inaconcordance with those studies; women who had knowledgeable of cervical cancer screening were 2.8 times more likely to uptake cervical screening than those who did not know the screening.

Furthermore, the present study revealed that the knowledge of metastasis and bleeding are the outcome of untreated $\mathrm{CC}$ which is due to luck of cervical cancer screening uptake. Those women who knew metastasis and

Page $11 / 18$ 
bleeding were 2.2 and 3.1 times more likely to utilize CC screening, respectively, than those who did not knew the advanced cervical cancer. Bezabih and his colleagues revealed that the risk of invasive cervical cancer is 10.3 times higher among women who had more than 4 children (37). This finding is in agreement with our result multipara women were 2.7 times more likely to uptake cervical screening than null para women.

The main reason for not up taking the cervical cancer screening were self-perceived health (85.8\%), lack of information (13.4\%), and fear of screening test result (2.8\%). This result also in harmony with studies conducted in Hossana, southern Ethiopia (53) and Addis Ababa (54) that indicated a lack of information and awareness were barriers to CC screening uptake. Cluster-randomized trial study conducted in Butajira district showed that self-assertion of being healthy and fear of screening were the main reason for non-utilizing screening services (55).

\section{Conclusion}

In this study, cervical cancer screening uptake is low. Knowledge about CC screening, had discussion with HCP about cervical cancer screening, and knowledge metastasis and bleeding as they are the consequences of advanced $\mathrm{CC}$ were the main predictors of cervical cancer screening uptake. Therefore, this study result call urgent interventions by all stockholders and specially the health sector should give priority on continues promotions to equip the women with good knowledge about CC screening and ensure its utilization through securing its availability and accessibility for all eligible women at all levels.

\section{Abbreviations}

AOR: Adjusted odds ratio

Cl: Confidence Interval

COR: Crude Odds Ratio

CC: Cervical cancer

HPV: Human papilloma virus

LMICs: Low and middle incomes countries

SSA: Sub-Saharan Africa

VIA: Visual inspection with Acetic Acid

WHO: World Health Organization

\section{Declarations}

- Ethics approval and consent to participate 
The study was approved by the ethical Review committee of the College of Medicine and Health Sciences (CMHS-ERC) of Ambo University, Ethiopia and all performed procedures were in accordance with the 1964 Helsinki declaration and its later amendments. Written informed consent was sought from all participants after the aim of the study was introduced. Confidentiality of the gathered information was assured to the interviewee.

\section{- Consent for publication}

Not applicable

\section{- Availability of data and materials}

The datasets used and /or analyzed during the current study are available from the corresponding author on reasonable request.

\section{- Competing interests}

The authors declare that they have no competing interests

\section{- Funding}

No funding was obtained for this study

\section{- Authors' contributions}

SHFN \& DTSN: involved in the proposal development, analysis and interpretation of the data and prepared the manuscript. WW and MKN: involves in the preparations of the manuscript and reviewing the paper. All authors read and approved the final manuscript

\section{- Acknowledgements}

We are grateful to Ambo University for supporting this research. Additionally, the authors would like to thank the study participants, data collectors and supervisors.

\section{References}

1. Bray F, Ferlay J, Soerjomataram I, Siegel RL, Torre LA, Jemal A. Global cancer statistics 2018: GLOBOCAN estimates of incidence and mortality worldwide for 36 cancers in 185 countries. CA Cancer J Clin. 2018;68(6):394-424.

2. Cervical Cancer. 2018. Available from: http://www.who.int/cancer/prevention/ diagnosisscreening/cervical-cancer/en/

3. Crosbie EJ, Einstein MH, Franceschi S, Kitchener HC. Human papillomavirus and cervical cancer. Lancet. 2013;382:889-99.

4. Arbyn M, Weiderpass E, Bruni L, de Sanjosé S, Saraiya M, Ferlay J, et al. Estimates of incidence and mortality of cervical cancer in 2018: a worldwide analysis. Lancet Glob Heal. 2019;8(2):e191-203. 
Available from: https://doi.org/10.1016/ S2214-109X(19)30482-6

5. Cohen PA, Jhingran A, Oaknin A, Denny L. Cervical cancer. Lancet 2019;393(10167):169-82. Available from: http://dx.doi.org/10.1016/S0140-6736(18)32470-X

6. Pimple S, Mishra G, Shastri S. Global strategies for cervical cancer prevention. Curr Opin Obstet Gynecol. 2016;28(1):4-10.

7. Vu M, Yu J, Awolude OA, Chuang L. Cervical cancer worldwide. Curr Probl Cancer. 2018;42(5):457-65.

8. Bosch FX, Broker TR, Forman D, Moscicki A-B, Gillison ML, Doorbar J, et al. Comprehensive Control of Human Papillomavirus Infections and Related Diseases. Vaccine. 2013;31S:F1-31. Available from: http://dx.doi.org/10.1016/ j.vaccine.2013.10.001

9. De Vuyst H, Alemany L, Lacey C, Chibwesha CJ, Sahasrabuddhe V, Banura C, et al. The burden of human papillomavirus infections and related diseases in sub-saharan Africa. Vaccine. 2013;31S:F32-46. Available from: http://dx.doi.org/10.1016/ j.vaccine.2012.07.092

10. Ferlay J, Shin HR, Bray F, Forman D, Mathers C, Parkin DM. Estimates of worldwide burden of cancer in 2008: GLOBOCAN 2008. Int J Cancer. 2010;127(12):2893-917.

11. Hull R, Mbele M, Makhafola T, Hicks C, Wang S, Reis R, et al. Cervical cancer in low and middle-income countries (Review). Oncol Lett. 2020;20(3):2058-74.

12. Mboumba Bouassa RS, Prazuck T, Lethu T, Jenabian MA, Meye JF, Bélec L. Cervical cancer in sub-Saharan Africa: a preventable noncommunicable disease. Expert Rev Anti Infect Ther. 2017;15(6):613-27. Available from: https://doi.org/10.1080/ 14787210.2017.1322902

13. Human Papillomavirus and Related Diseases Report. 2016. Available from: www.hpvcentre.com

14. Human Papillomavirus and Related Cancers. 2010. Available from: https://www.unav.edu/documents/16089811/16216616/HPVReport2010.pdf

15. Comprehensive Cervical Cancer Control. Geneva. 2014.

16. Draft: Global Strategy Towards the Elimination of Cervical Cancer As A Public Health Problem. Who 2019; (December). Available from: https://www.who.int/docs/ default-source/documents/cervical-cancerelimination-draft-strategy.pdf

17. Drolet M. Population-level impact and herd effects following human papillomavirus vaccination programmes: a systematic review and meta-analysis. Lancet Infect Dis. 2015;15(5):565-580.

18. Ronco G, Dillner J, Elfström KM, Tunesi S, Snijders PJF, Arbyn M, et al. Efficacy of HPV-based screening for prevention of invasive cervical cancer: Follow-up of four European randomised controlled trials. Lancet. 2014;383(9916):524-32. Available from: http://dx.doi.org/10.1016/S0140-6736(13)62218-7

19. Ogilvie GS, Van Niekerk D, Krajden M, Smith LW, Cook D, Gondara L, et al. Effect of Screening with Primary Cervical HPV Testing vs Cytology Testing on High-grade Cervical Intraepithelial Neoplasia at 48 Months: The HPV FOCAL Randomized Clinical Trial. Obstet Gynecol Surv. 2018;73(11):632-4.

20. Toliman PJ, Kaldor JM, Tabrizi SN, Vallely AJ. Innovative approaches to cervical cancer screening in lowand middle-income countries. Climacteric. 2018;21(3):235-8. Available from: https://doi.org/10.1080/13697137.2018.1439917

21. Sankaranarayanan R. Screening for cancer in low- and middle-income countries. Ann Glob Heal. 2014;80(5):412-7. Available from: http://dx.doi.org/10.1016/ j.aogh.2014.09.014 
22. Sankaranarayanan R, Esmy PO, Rajkumar R, Muwonge R, Swaminathan R, Shanthakumari S, et al. Effect of visual screening on cervical cancer incidence and mortality in Tamil Nadu, India: a cluster-randomised trial. Lancet. 2007;370(9585):398-406.

23. Lon S. Schneider MD et al. HPV Screening for Cervical Cancer in Rural India. N Engl J Med. 2015;687-96.

24. Guidelines for screening and treatment of precancerous lesions for cervical cancer prevention. WHO Guidel. 2013;60. Available from: http://www.who.int/

reproductivehealth/publications/cancers/screening_and_treatment_of_precancerous_lesions/en/index.html

25. Curry SJ, Krist AH, Owens DK, Barry MJ, Caughey AB, Davidson KW, et al. Screening for cervical cancer us preventive services task force recommendation statement. JAMA - J Am Med Assoc. 2018;320(7):674-86.

26. Landy R, Pesola F, Castañón A, Sasieni P. Impact of cervical screening on cervical cancer mortality: Estimation using stage-specific results from a nested case-control study. Br J Cancer. 2016;115(9):1140-6.

27. Baezconde-Garbanati L, Agurto I, Gravitt PE, Luciani S, Murphy S, Ochoa C, et al. Barriers and innovative interventions for early detection of cervical cancer. Salud Publica Mex. 2019;61(4):456-60.

28. Gele AA, Qureshi SA, Kour P, Kumar B, Diaz E. Barriers and facilitators to cervical cancer screening among Pakistani and somali immigrant women in Oslo: A qualitative study. Int J Womens Health. 2017;9:487-96.

29. Lea CS, Perez-Heydrich C, Des Marais AC, Richman AR, Barclay L, Brewer NT, et al. Predictors of Cervical Cancer Screening among Infrequently Screened Women Completing Human Papillomavirus Self-Collection: My Body My Test-1. J Women's Heal. 2019;28(8):1095-104.

30. Denny L. Control of Cancer of the Cervix in Low- and Middle-Income Countries. Ann Surg Oncol. 2015;22(3):728-33.

31. Ndejjo R, Mukama T, Kiguli J, Musoke D. Knowledge, facilitators and barriers to cervical cancer screening among women in Uganda: A qualitative study. BMJ Open. 2017;7(6):1-8.

32. Yang H, Li SP, Chen Q, Morgan C. Barriers to cervical cancer screening among rural women in eastern China: A qualitative study. BMJ Open. 2019;9(3):1-8.

33. Lim JNW, Ojo AA. Barriers to utilisation of cervical cancer screening in Sub Sahara Africa: a systematic review. Eur J Cancer Care (Engl). 2017;26(1):1-9.

34. Musa J, Achenbach CJ, O’Dwyer LC, Evans CT, McHugh M, Hou L, et al. Effect of cervical cancer education and provider recommendation for screening on screening rates: A systematic review and meta-analysis. PLoS One. 2017;12(9):1-28. Available from: http://dx.doi.org/10.1371/journal.pone.0183924

35. Racey CS, Gesink DC. Barriers and Facilitators to Cervical Cancer Screening Among Women in Rural Ontario, Canada: The Role of Self-Collected HPV Testing. J Rural Heal. 2016;32(2):136-45.

36. Getahun F, Mazengia F, Abuhay M, Birhanu Z. Comprehensive knowledge about cervical cancer is low among women in Northwest Ethiopia. BMC Cancer. 2013;13(2). Available from: BMC Cancer

37. Bezabih M, Tessema F, Sengi H, Deribew A. Risk Factors Associated with Invasive Cervical Carcinoma among Women Attending Jimma University Specialized Hospital, Southwest Ethiopia: A Case Control Study. Ethiop J Health Sci. 2015;25(4):345-52.

38. Agam B. Bansal, Abhijit P. Pakhare, Neelkamal Kapoor RM and AMK. Knowledge, attitude, and practices related to cervical cancer among adult women: A hospital-based cross-sectional study. J Nat Sci Biol Med. 2015;6(2):324-328. 
39. Collaboration GB of DC. Global, regional, and national cancer incidence, mortality, years of life lost, years lived with disability, and disability-adjusted life-years for 32 cancer groups, 1990 to 2015: A systematic analysis for the global burden of disease study. JAMA Oncol. 2017;3(4):524-48.

40. Idowu A, Olowookere SA, Fagbemi AT, Ogunlaja OA. Determinants of Cervical Cancer Screening Uptake among Women in Ilorin, North Central Nigeria: A Community-Based Study. J Cancer Epidemiol. 2016;

41. Aweke YH, Ayanto SY, Ersado TL. Knowledge, attitude and practice for cervical cancer prevention and control among women of childbearing age in Hossana Town , Hadiya zone, Southern Ethiopia: Community-based cross-sectional study. 2017;1-18. Available from: http://dx.doi.org/10.1371/journal.pone.0181415

42. Tefera F, Mitiku I. Uptake of Cervical Cancer Screening and Associated Factors Among 15 - 49-Year-Old Women in Dessie Town , Northeast Ethiopia. 2017;901-7.

43. Bayu H, Berhe Y, Mulat A, Alemu A. Cervical Cancer Screening Service Uptake and Associated Factors among Age Eligible Women in Mekelle Zone, Northern Ethiopia , 2015: A Community Based Study Using Health Belief Model. 2016;1-13. Available from: http://dx.doi.org/10.1371/journal.pone.0149908

44. Bante SA, Getie SA, Getu AA, Mulatu K. Uptake of pre-cervical cancer screening and associated factors among reproductive age women in Debre Markos town , Northwest Ethiopia , 2017. 2019;1-9.

45. Gebregziabher D, Berhanie E, Birhanu T, Tesfamariam K. Correlates of cervical cancer screening uptake among female under graduate students of Aksum University , College of Health Sciences ,. BMC Res Notes. 2019;1-6. Available from: https://doi.org/10.1186/s13104-019-4570-z

46. Agide FD, Garmaroudi G, Sadeghi R, Shakibazadeh E, Yaseri M, Koricha ZB, et al. A systematic review of the effectiveness of health education interventions to increase cervical cancer screening uptake. 2018;1-7.

47. Yeserah B, Id A, Anteneh KT, Enyew MM. Utilization of cervical cancer screening and associated factors among women in Debremarkos town , Amhara region, Northwest Ethiopia: Community based crosssectional study. 2020;578:1-13. Available from: http://dx.doi.org/10.1371/journal.pone.0231307

48. Ruddies F, Gizaw M, Teka B, Thies S, Wienke A, Kaufmann AM, et al. Cervical cancer screening in rural Ethiopia: a cross- sectional knowledge, attitude and practice study. 2020;1-10.

49. Kasa AS, Tesfaye TD, Temesgen WA. Knowledge, attitude and practice towards cervical cancer among women in Finote Selam. Afr Health Sci. 2018;18(3):623-36.

50. Id HT, Gebremariam L, Kahsay T, Berhe K. Factors affecting utilization of cervical cancer screening services among women attending public hospitals in Tigray region , Ethiopia , 2018; Case control study. 2019;1-11. Available from: http://dx.doi.org/10.1371/journal.pone.0213546

51. Teame H, Addissie A, Ayele W, Hirpa S, Gebremariam A, Gebreheat G, et al. Factors associated with cervical precancerous lesions among women screened for cervical cancer in Addis Ababa, Ethiopia: A case control study. 2018;39:1-13. Available from: http://dx.doi.org/10.1371/journal.pone.0191506

52. Muluneh BA, Atnafu DD. Predictors of cervical cancer screening service utilization among commercial sex workers in Northwest Ethiopia: a case- control study. 2019;1-9.

53. Habtu Y, Yohannes S, Laelago T. Health seeking behavior and its determinants for cervical cancer among women of childbearing age in Hossana Town , Hadiya zone, Southern Ethiopia : community based cross sectional study. 2018;1-9. 
54. Ababa A, Fentie AM, Tadesse TB, Gebretekle GB. Factors affecting cervical cancer screening uptake, visual inspection with acetic acid positivity and its predictors among women attending cervical cancer screening service. 2020;1-10.

55. Gizaw M, Teka B, Ruddies F, Kassahun K, Worku D, Worku A et al. Reasons for Not Attending Cervical Cancer Screening and Associated Factors in Rural Ethiopia. Cancer Prev Res. 2020;13(7):593-600.

\section{Figures}

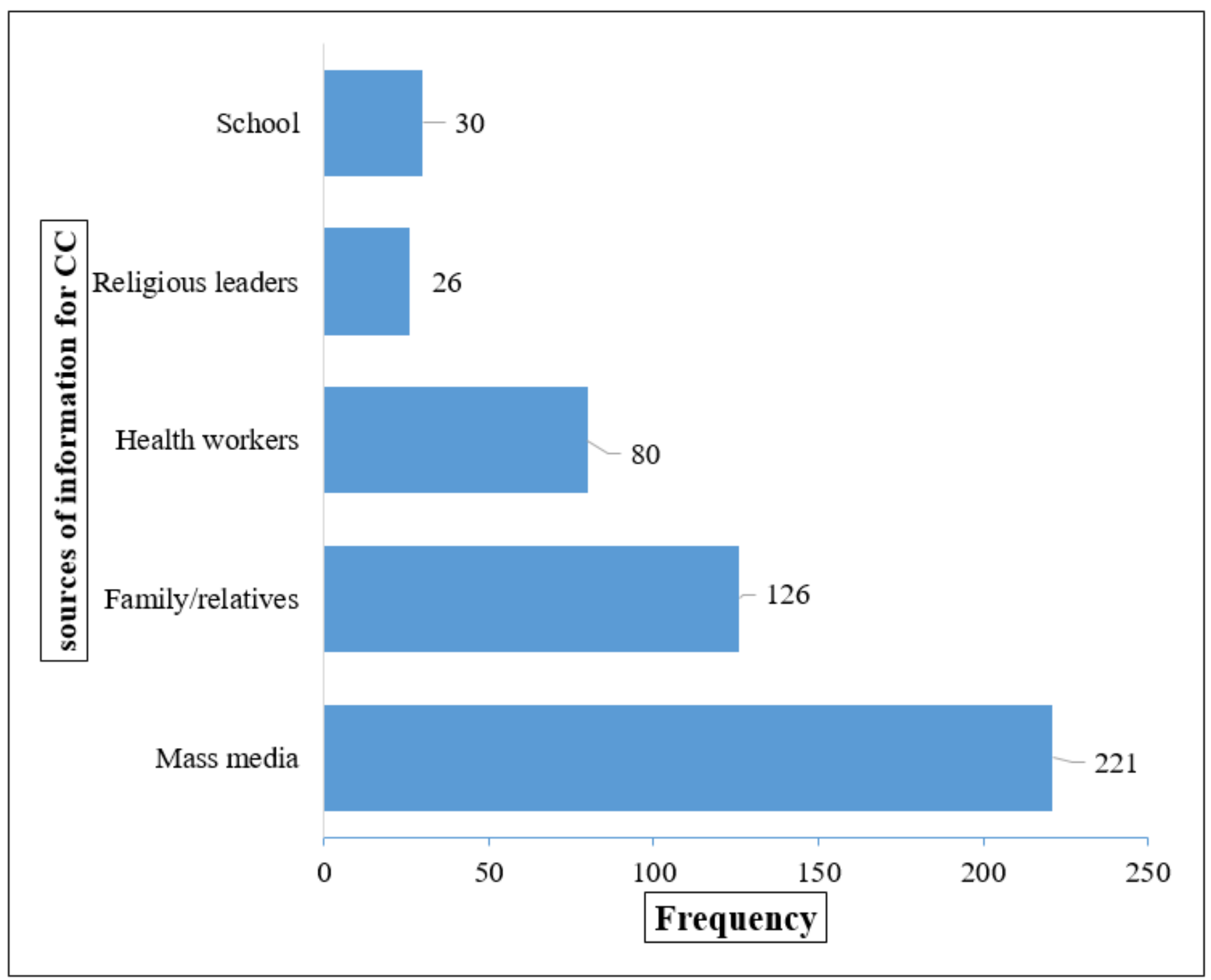

\section{Figure 1}

Sources of information of cervical cancer reported by the study subjects (multiple responses were considered; thus the sum might be more than sample size) 


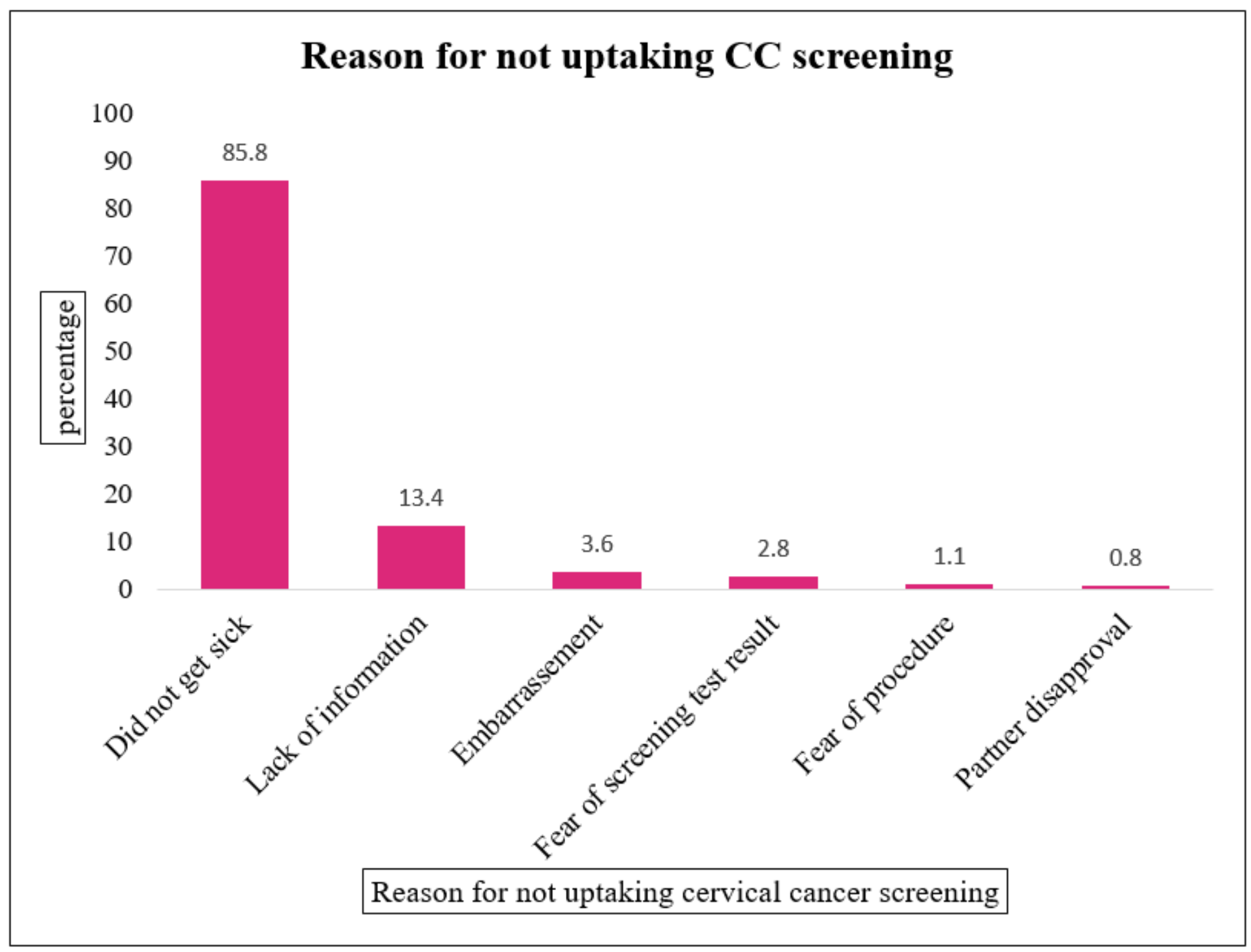

Figure 2

Main reason for not up-taking cervical cancer screening by women of Ambo town, western Oromia, Ethiopia, December-January 2017 